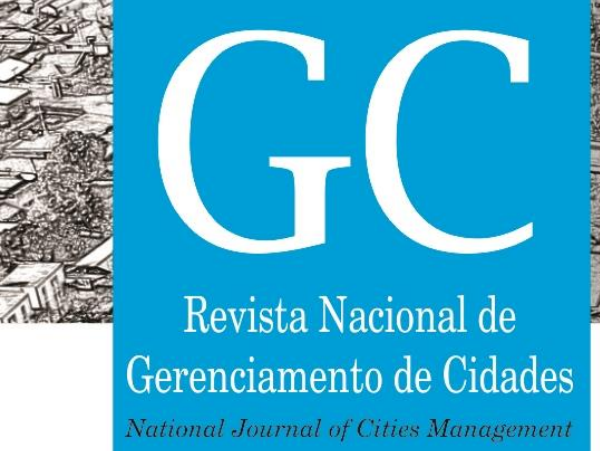

\title{
Praça Rui Barbosa: cronotopo atual, memória e identidade
}

Rui Barbosa Square: current chronotope, memory and identity

Plaza Rui Barbosa: cronotopo actual, memoria y identidad

Mariana Maia da Cruz Fernandes

Mestranda PPGARQ, UNESP, Brasil. marianamaia.cruzf@gmail.com

Rosío Fernández Baca Salcedo

Professora Doutora PPGARQ, UNESP, Brasil. rosiofbs@faac.unesp.br 


\title{
1 INTRODUÇÃO
}

Presente nas cidades brasileiras desde o Brasil colonial, a Praça Matriz (defronte às Igrejas Matriz) é uma característica geral das povoações antigas (MARX, 1980). Marx ainda ressalta que eram essas praças que constituíam o principal polo urbano, com as residências mais abastadas, os principais comércios e também as atividades de lazer: "[...] era o espaço de interação de todos os elementos da sociedade, abarcando os vários estratos sociais. Era ali que a população da cidade colonial manifestava sua territorialidade [...]" (ROBA; MACEDO, 2003, p. 22)

Segundo Alex (2008) a Praça Matriz é um dos elementos que constituem o cerne dos espaços urbanos abertos, onde se reflete um determinado ideal de vida em um determinado momento da história. Diante disso, Lamas (2014) complementa:

\begin{abstract}
A praça pressupõe a vontade e o desenho de uma forma e de um programa. Se a rua, o traçado, são os lugares de circulação, a praça é o lugar intencional do encontro, da permanência, dos acontecimentos, de práticas sociais, de manifestações de vida urbana e comunitária e de prestígio, e, consequentemente, de funções estruturantes e arquitecturas significativas. (LAMAS, 2014, p. 100 e 102).
\end{abstract}

Lamas também ressalta que "A praça reúne a ênfase do desenho urbano como espaço colectivo de significação importante." (LAMAS, 2014, p. 102), ainda em contribuição à caracterização das praças, Carvalho et al (2004), ao citarem Habermas ${ }^{1}$, relatam que o espaço público é o local onde a "opinião pública" se forma, acontecendo assim uma ligação entre sociedade e estado:

\begin{abstract}
[...] devemos entender a praça como o espaço público por excelência, o lugar onde o individual torna-se coletivo, o privado torna-se público e o público forma a opinião pública. Mais que lugar de lazer, a praça é o lugar da cidadania. $\mathbf{O}$ declínio da praça é o declínio da esfera pública, da política e do cidadão. (CARVALHO et al, 2004, p. 12, grifo dos autores).
\end{abstract}

A caracterização das praças também pode ser dada sobre o olhar da dialogia, onde é tida a relação de um objeto, ou texto, com o seu contexto; nesse caso aqui abordado, tem-se a Praça Matriz em relação ao seu contexto urbano (a sociedade e gestão urbana, por exemplo); como diz Muntañola, a arquitetura é "[...] dependiente del contexto, o sea determinada por el contexto histórico cultural a través de poder simbólico [...]"2 (MUNTAÑOLA, 2011, p. 33). Sobre a dialogia:

[...] la noción «arquitectónica» está indisolublemente unida a la de "contestabilidad» ("conversatilidad») (answerability) o sea, a la capacidad de dirigirse a alguien o a algo desde otro alguien u otro algo. Esta capacidad de «dirigirse» (to address) es esencial en la teoría dialógica del «o versar» (con-versar) que presupone una intensión de dirigirse,

\footnotetext{
${ }^{1}$ HABERMAS, Jurgen. Mudança estrutural na esfera pública. Rio de Janeiro: Tempo Brasileiro, 1984.

2 "[...] dependente do contexto, ou seja, é determinada pelo contexto histórico cultural através do poder simbólico [...]" (MUNTAÑOLA, 2011, p. 33, tradução dos autores)
} 


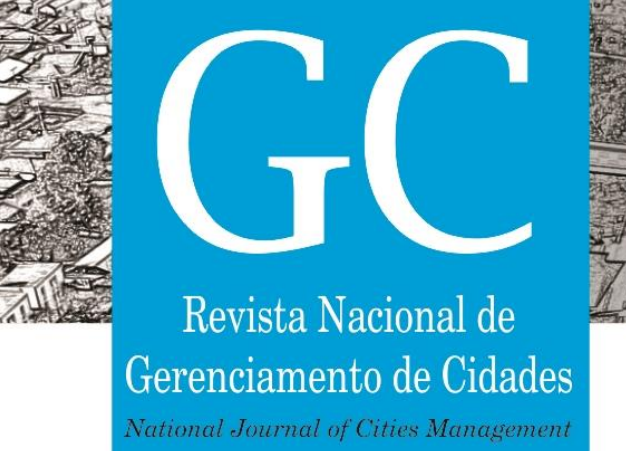

\section{OBJETIVOS}

Este trabalho tem como objetivo caracterizar a Praça Rui Barbosa em seu cronotopo atual (2017), segundo seus ambientes físico, social e simbólico, compreendendo o espaço a partir do urbanismo dialógico como método de análise.

\section{MÉTODO URBANISMO DIALÓGICO}

O urbanismo dialógico tem como base a fundamentação teórica e filosófica de Bakhtin (1997), Muntañola (2006; 2011) e Zárate (2014; 2015), onde se estuda a relação do texto (Praça Matriz) com seu contexto urbano, nos ambientes: físicos, sociais e simbólicos de seu cronotopo atual. No contexto urbano são caracterizadas a atual Praça Rui Barbosa com base em questionários aplicados à população e a atuação da Câmara Municipal.

No texto ou Praça Matriz são caracterizados ambientes físicos, sociais e simbólicos. No ambiente físico é apresentado o projeto atual (cedido pela Secretaria Municipal de Planejamento de Bauru - SEPLAN) No ambiente social é registrado as atividades realizadas na praça. No ambiente simbólico é registrado a identidade e memória coletiva.

\section{A PRAÇA MATRIZ DE BAURU}

Primeiramente, é de grande importância uma pequena contextualização histórica. O local onde atualmente está inserida a Praça Rui Barbosa já abrigou a primeira capela erguida na Vila de Bauru, em 20 de abril de 1888, tendo sido dedicada ao Espírito Santo. Ao longo dos anos surgiram discordâncias entre Igreja e Câmara Municipal, resultando na demolição da primeira capela (em madeira), para ceder o lugar para a primeira praça da cidade, a então Praça Municipal, inaugurada em $1914 .^{4}$

Em sequência, parte-se então para a caracterização da Praça nos ambientes físico, social e simbólico em relação ao cronotopo atual (2017). Para a obtenção dos dados, apresentados a seguir, foi realizado questionário com a população de Bauru, em setembro de 2017, tendo um alcance de 35 pessoas $^{5}$. As respostas são classificadas e analisadas, de forma a serem extraídas a maior quantidade possível de informação para a fiel caracterização do cronotopo atual.

A seguir são apresentadas as características dos entrevistados: faixa etária e tempo de permanência em Bauru.

\footnotetext{
${ }^{4}$ As informações apresentadas no parágrafo assim como maiores detalhes acerca o assunto (que não são o objetivo deste trabalho), se encontram na bibliografia abaixo:

Notícias do jornal Bauru llustrado, durante vários anos;

GHIRARDELLO, Nilson. Aspectos do direcionamento urbano da cidade de Bauru. 1992, 187f. Dissertação (Mestrado em Arquitetura) - Escola de Engenharia de São Carlos da Universidade de São Paulo, São Carlos, 1992.

${ }^{5} \mathrm{O}$ presente trabalho faz parte de uma pesquisa ainda em desenvolvimento para obtenção de título de mestre.
} 


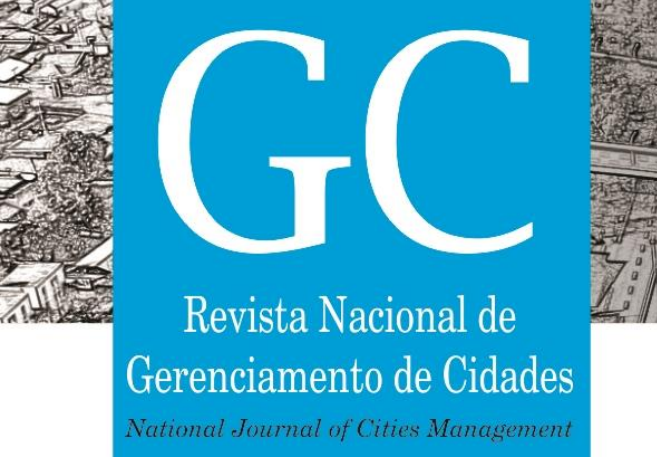

- Em relação a faixa etária: 8,57\% estão entre os 20 e 35 anos; $20 \%$ estão entre os 36 e 50 anos; $57,14 \%$ estão entre os 51 e 65 anos; e 14,28\% estão entre os 66 e 75 anos.

- Em relação ao tempo de morada em Bauru: 2,85\% residem entre 10 e 19 anos; $17,14 \%$ residem entre 20 e 35 anos; $40 \%$ residem entre 36 e 50 anos; 31,42\% residem entre 51 e 65 anos; 5,71\% residem entre 66 e 75 anos; e 5,71\% não especificaram.

\subsection{Ambiente físico}

O ambiente físico da Praça Rui Barbosa corresponde ao último projeto implementado pela Prefeitura Municipal de Bauru no ano de 2015 (planta baixa e dados gerais fornecidos pela SEPLAN). Porém, decorridos aproximadamente apenas dois anos da última "revitalização", já é possível notar a falta de manutenção que o espaço apresenta.

A Praça da Matriz é caracterizada em seu ambiente físico por um projeto definido por traçados retilíneos; para o paisagismo existem canteiros ao nível do chão e canteiros elevados, alguns desse elevados apresentam bancos em concreto; uma "passarela" em pastilhas cerâmicas que atravessa o espaço da praça levando à porta de entrada da Catedral do Espírito Santo; piso de sinalização para deficientes visuais; o Coreto, implantado na gênese da praça em 1914; postes de iluminação; a fonte, implantada na revitalização de 1990; um arco em concreto, localizado na passarela, em lado oposto à Catedral; bicicletários; bancos de base em concreto e assento em madeira; lixeiras; obelisco; escultura; busto de Rui Barbosa; ponto de táxi; sanitários feminino e masculino; bebedouros; e a vegetação. Conforme Figura 1.

Sobre a vegetação, esta é constituída por árvores de grande porte, palmeiras, vegetação de pequeno porte e forrações. Apesar da existência de árvores de grande porte, o sombreamento fornecido por elas não é suficiente para os usuários da praça, pois o município de Bauru apresenta temperaturas elevadas até mesmo nas estações de outono e inverno, o que causa grande desconforto no período diurno. Já em relação ao período noturno, o sombreamento fornecido pelas árvores é intenso, quando em comparação com a iluminação existente; muitos bauruenses não se sentem seguros nem ao menos em passar pela Praça Rui Barbosa no período noturno devido à grande "escuridão" que há em alguns pontos da praça.

Na Figura 1 também é possível notar os pontos de maior sombreamento no período noturno, sendo o centro da praça (imediações da passarela) o local mais iluminado e de circulação mais livre. Na sequência são apresentadas algumas imagens referente à praça, com o ângulo das tomadas de fotografia representadas na planta baixa.

Na Figura 2 é possível notar que os canteiros elevados que circundam a praça causam uma barreira visual tanto para aqueles que estão no exterior da praça, quanto para aqueles que estão no interior. A vegetação de grande porte e sem as devidas podas contribuem ainda mais para essa barreira. 


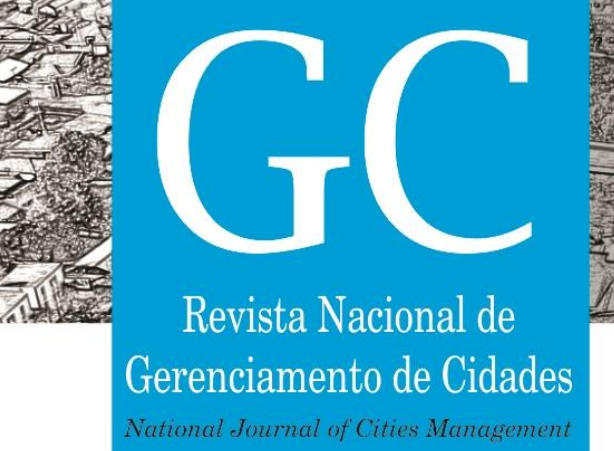

ISSN $2318=8472$
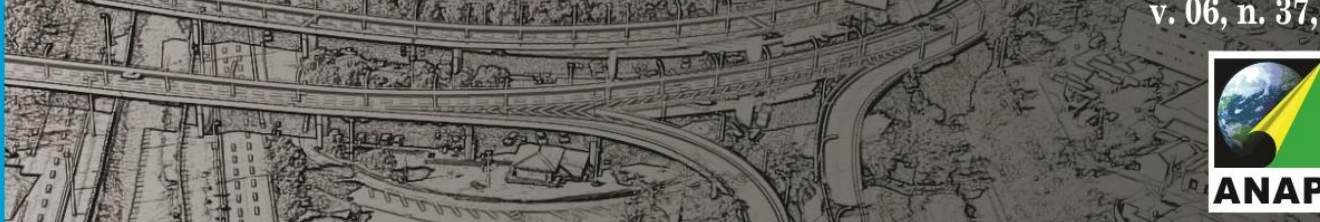

ANAP

Figura 1: Planta Baixa Praça Rui Barbosa; projeto de 2015.

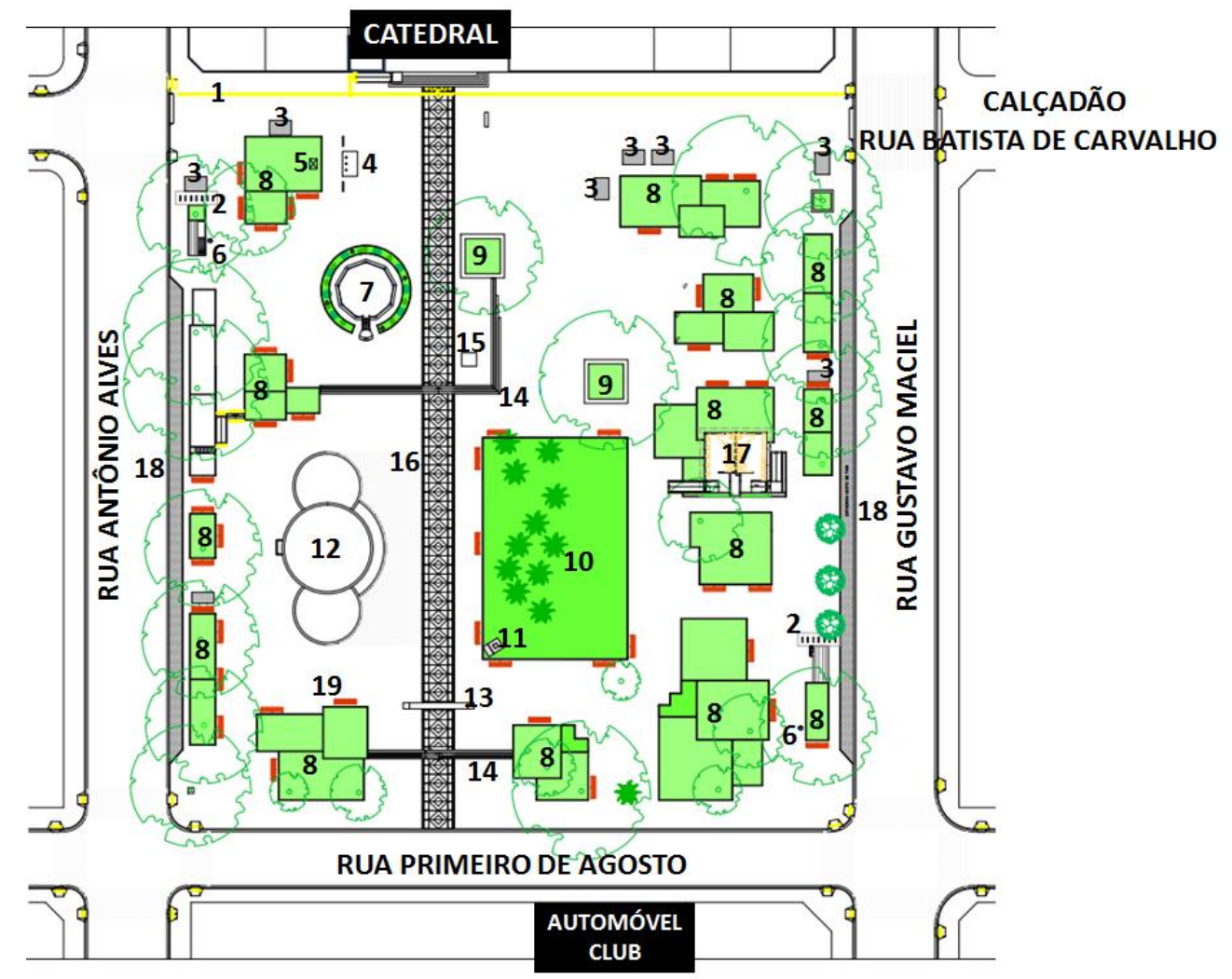

LEGENDA

1 - Piso Tátil

2- Bicicletário

3-Ambulantes

4 - Mastro para bandeiras

5 - Obelisco do cinquentenário

6 - Bebedouros

7- Coreto

8 - Canteiros elevados

9 - Canteiros elevados com bancos

10 - Canteiro no nível do piso

Fonte: SEPLAN; editado pelos autores (2017).
11 - Busto Rui Barbosa

12 - Fonte

13 - Arco em concreto

14 - Escadarias

15 - Escultura

16 - Passarela

17 - Sanitários

18 - Pontos de táxi

19 - Bancos 


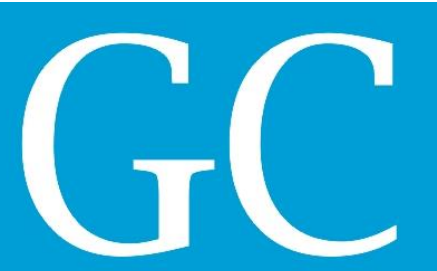

Revista Nacional de Gerenciamento de Cidades National Joumal of Cities Management

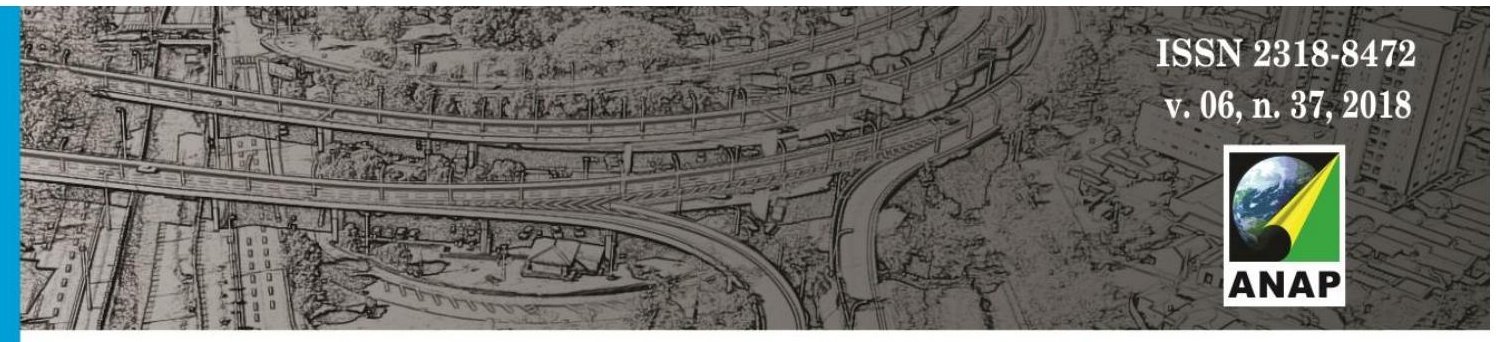

Figura 2: Canteiros elevados com vegetação de grande porte.
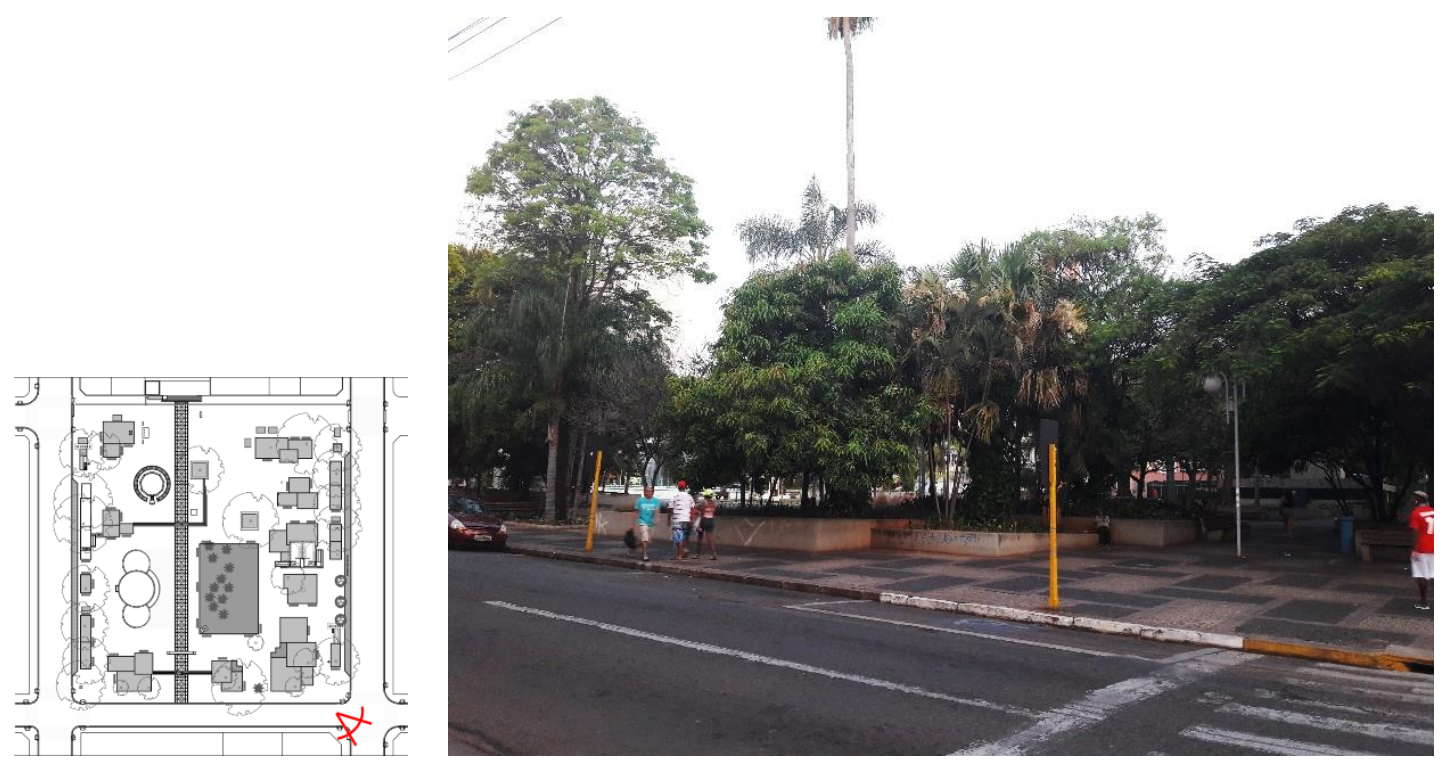

Fonte: Acervo Fernandes; out. 2017.

Figura 3: Vista central da Praça Rui Barbosa.
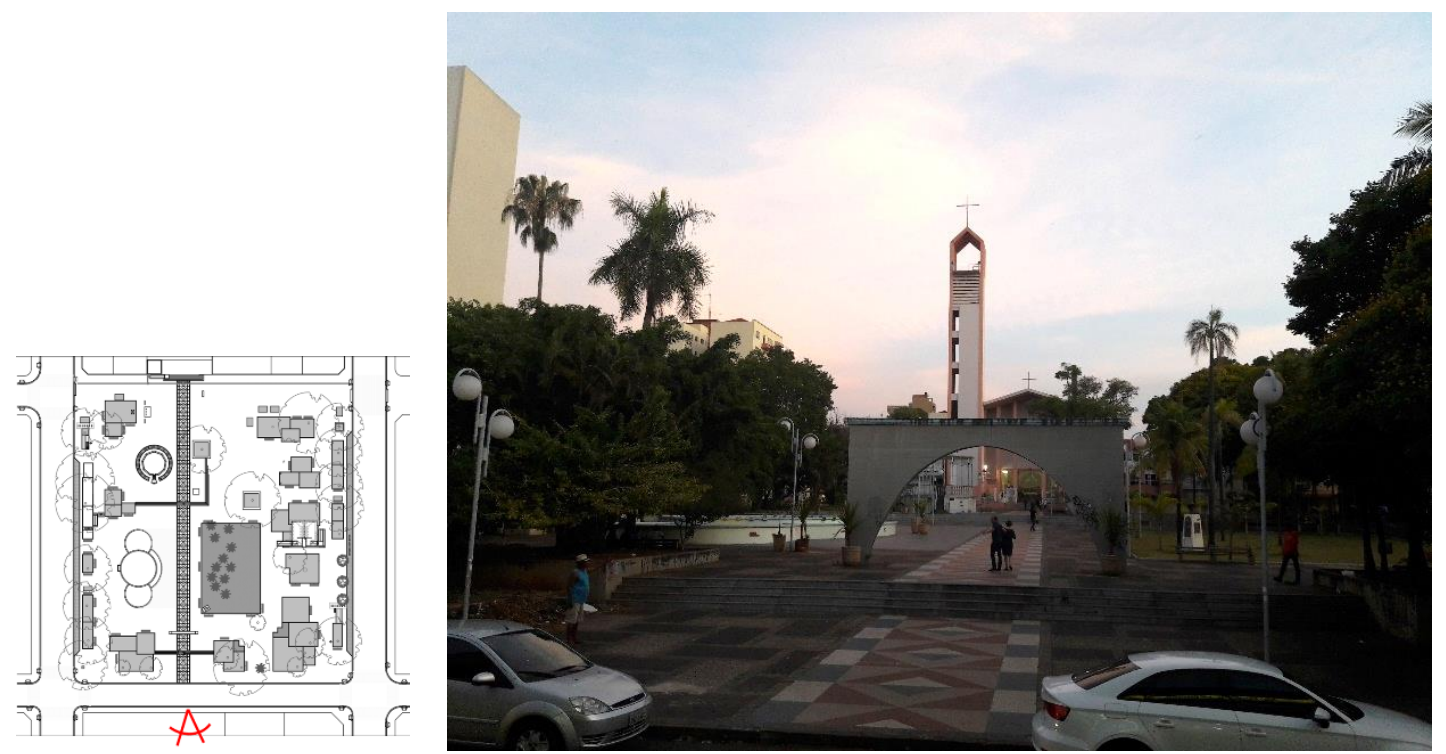

Fonte: Acervo Fernandes; out. 2017.

Na Figura 3, acima, é possível ver a existência de alguns poucos postes de iluminação, que em sua maioria localizam-se em torno da passarela. A frente é possível notar o Arco em concreto, e ao fundo, a torre da Catedral. É possível notar a ausência de vegetação ao centro da praça, 


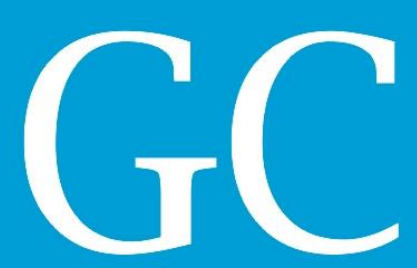

Revista Nacional de

Gerenciamento de Cidades

National Journal of Cities Management

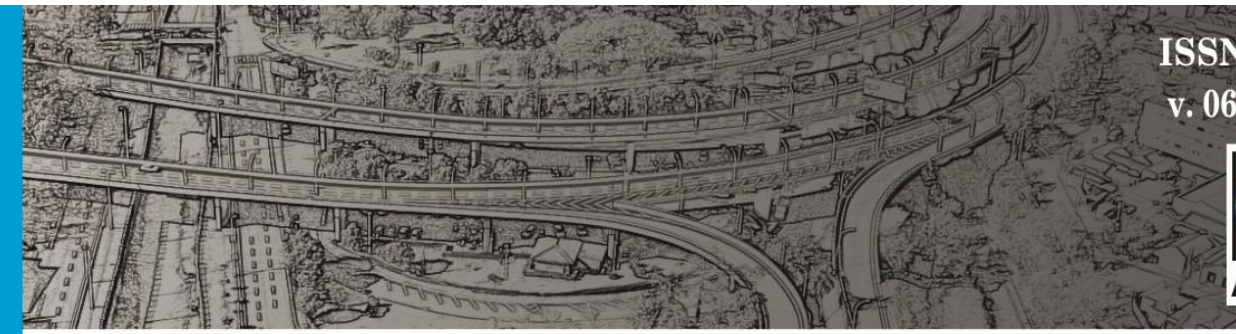

enquanto que nas laterais há grande concentração de vegetação de grande porte. Visualiza-se ainda a fonte, na lateral esquerda.

A Figura 4, abaixo, mostra o sombreamento noturno causado pelas árvores de grande porte logo ao entardecer (por volta das 18:30h), onde soma-se a falta de manutenção da iluminação pública, o que agrava a sensação de insegurança da população. Através dos questionários soubese que atualmente a praça é local para usuários de drogas ilícitas até mesmo no período diurno; esse fato pode ser comprovado pelos autores no momento das tomadas de fotografia, sendo os locais de pouca iluminação, os escolhidos por essa parcela da população que faz uso da Praça Rui Barbosa.

Ainda na imagem abaixo, é possível visualizar o bicicletário; o ponto de táxi, na lateral direita; alguns bancos em base de concreto e assentos e encostos em madeira.

Figura 4: Sombreamento noturno e falta de manutenção da iluminação.
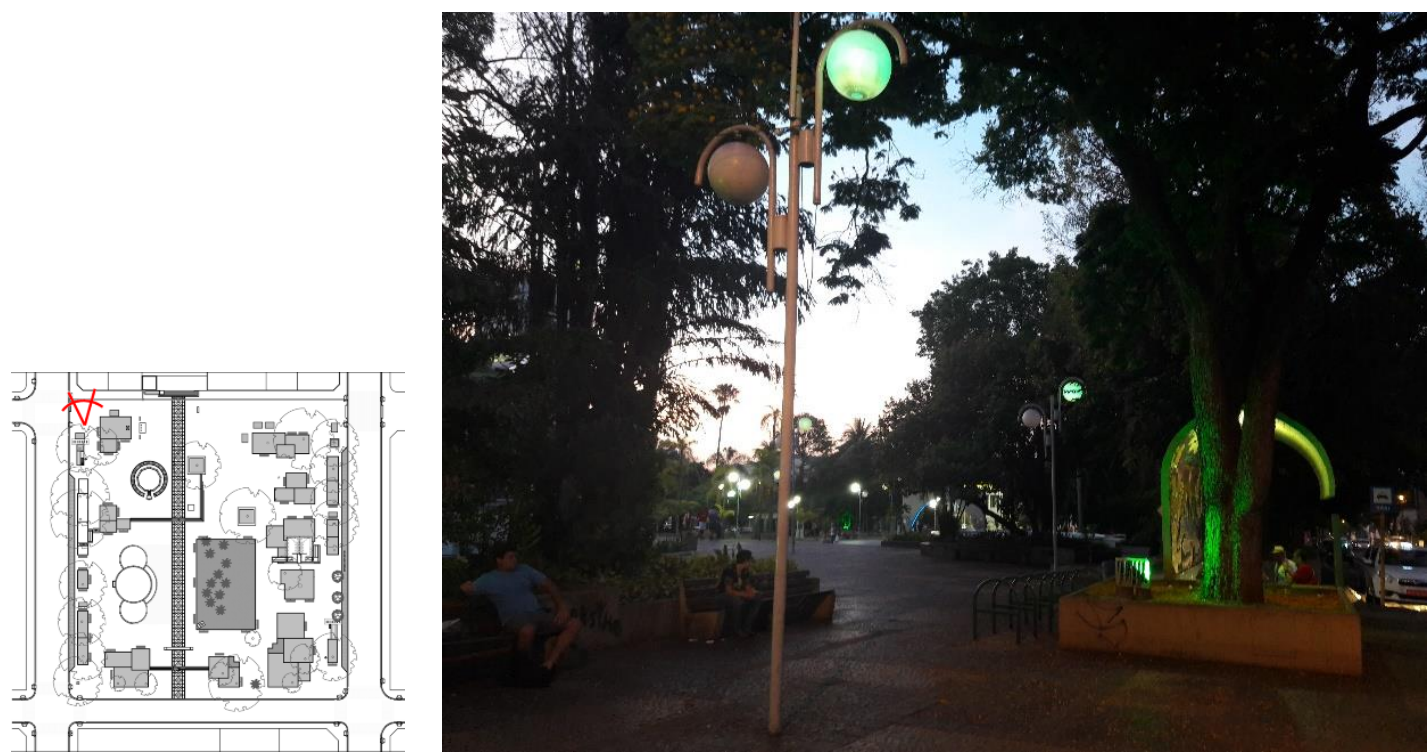

Fonte: Acervo Fernandes; out. 2017.

\subsection{Ambiente social}

O uso social que a Praça Matriz de Bauru apresenta está extremamente atrelado ao ambiente físico que ela apresenta e à percepção que a população tem do espaço urbano, que nesse caso, em sua grande maioria, a sensação que a praça transmite é de insegurança.

Quando perguntado à população bauruense, se atualmente utilizam a praça de alguma maneira, $82,85 \%$ das resposta foi que a utilizam somente como passagem, sendo muitas das vezes através de um meio de transporte particular; a justificativa em se utilizar a praça somente como 
passagem, ou até mesmo para encurtar um trajeto é a insegurança. Foi muito citado o medo de passar próximo aos usuários de drogas ilícitas e também dos ambulantes.

Apenas $14,28 \%$ das respostas obtidas utilizam o ambiente da praça para contemplação e passeio, na justificativa de que têm uma forma ligação afetiva com o espaço, e que ir ao local é uma forma de rememorar tempos passados. E somente $2,85 \%$ afirma não ter quaisquer envolvimento com a praça, nem mesmo a utilizando como passagem.

Ainda, de forma a compreender o motivo pelo qual a população bauruense não utiliza a praça na atualidade, por mais que se tenha o conhecimento de que a cultura do passear e se encontrar na praça possa estar quase extinta, a população foi questionada sobre gosto pela praça, se é um espaço agradável.

Diante dessa questão, 85,71\% responder não de forma bastante enfática, justificando esse não dando alguns adjetivos e qualidades à praça, além do próprio medo da insegurança. 0 sim, ficou para uma parcela de apenas $14,28 \%$, com justificativas que serão apresentadas abaixo, na Tabela 1 ; onde também serão apresentadas as respostas mais marcantes referentes ao não, juntamente com a quantidade de vezes em que foi mencionada.

Tabela 1: Justificativas em gostar ou não da Praça Rui Barbosa.

\begin{tabular}{ll}
\hline \multicolumn{2}{c}{ NÃO } \\
\hline Falta de segurança & 6 \\
\hline Muito concreto & 4 \\
\hline Usuários de drogas ilícitas & 4 \\
\hline Mal frequentada & 6 \\
\hline Triste & 3 \\
\hline Falta de atividades culturais & 3 \\
\hline Descaracterização do projeto & 8 \\
original (gênese) & \\
\hline Fria e impessoal & 4 \\
\hline Pouco verde & 5 \\
\hline Perda da identidade & 4 \\
\hline Seca e árida & 4 \\
\hline
\end{tabular}

\begin{tabular}{ll}
\hline \multicolumn{2}{c}{ SIM } \\
\hline $\begin{array}{l}\text { Existência de protestos } \\
\text { manifestações }\end{array}$ & 1 \\
\hline Patrimônio histórico & 1 \\
\hline Visual agradável & 1 \\
\hline Memória (afetividade) & 1 \\
\hline
\end{tabular}

Fonte: Autores, 2017.

A seguir, Figura 5, é possível notar que a parte central da Praça Rui Barbosa, a mais iluminada, não apresenta circulação alguma de pessoas, comprovando os medos citados pela população. Somente as laterais da praça apresentam uso, ou seja, as localidades sombreadas e com pouca iluminação pública (fato percebido também pelos autores no momento da visita à praça). 


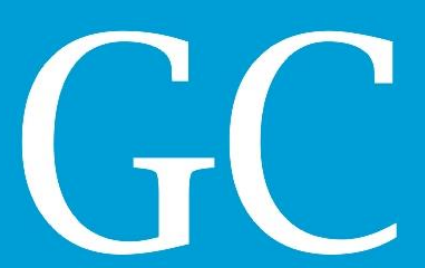

Revista Nacional de

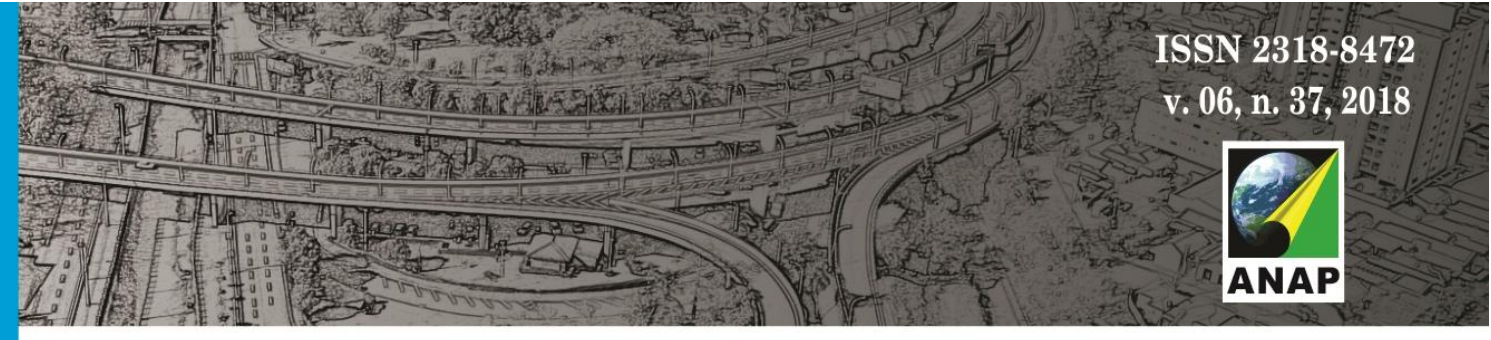

Gerenciamento de Cidades

National Journal of Cities Management

Pode-se então afirmar que, mesmo ainda existindo em pouca proporção o uso social tradicional, ou aquele provindo da gênese (passeio, lazer e contemplação), o uso social atual, que tem caracterizado a praça é o "uso marginal".

Estabelece-se essa nomenclatura (uso marginal), devido ao sentido literal encontrado no dicionário ${ }^{6}$, ou seja, é um uso que vive à margem da lei ou da sociedade, não respeitando as normas estabelecidas; o que causa afastamento por parte das demais parcelas da sociedade que não fazem parte daquela primeira citada.

Figura 5: Praça Rui Barbosa deserta.
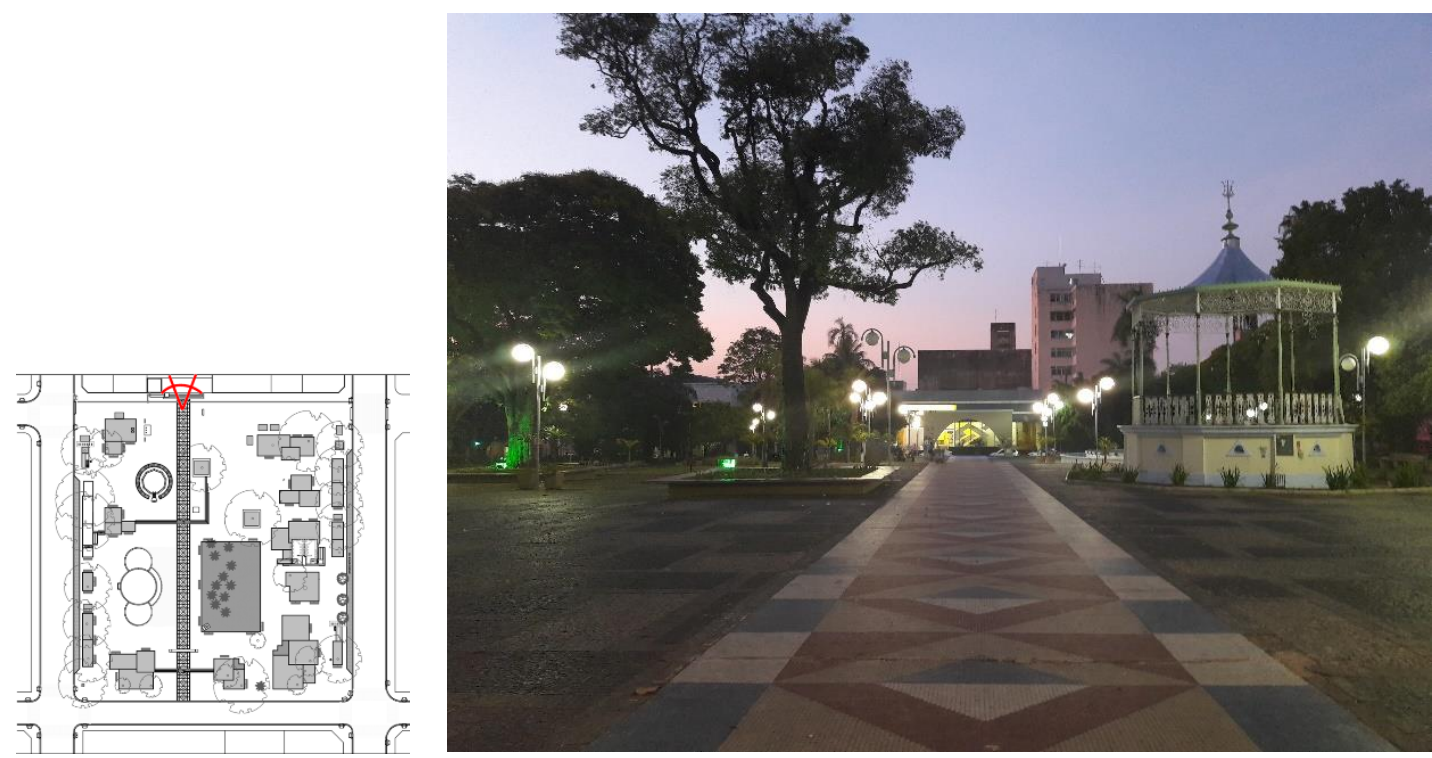

Fonte: Acervo Fernandes; out. 2017.

\subsection{Ambiente simbólico}

Ainda com base no questionário aplicado, foi possível levantar informações em relação à simbologia da praça para a população bauruense, ou seja, o que a praça de fato significa ou representa para essas pessoas, que utilizam ou não a praça na atualidade.

As respostas foram diversas, mas agrupando-as em assuntos de maior proximidade, tem-se:

- Para 61,36\% a praça tem um valor afetivo com o passado: uma rememoração da infância nos grandes lagos onde se viam jacarés e peixe, o passeio após as missas na companhia de pais e irmãos, o pipoqueiro, a banda que tocava no Coreto, e as brincadeiras antigas.

\footnotetext{
${ }^{6}$ Dicionário Michaelis on-line.
} 
- Para $15,90 \%$ a praça é a representação de um momento histórico importante pelo qual a cidade de Bauru passou, sendo chamada por alguns de "a principal praça" ou de "marco".

- Para $13,63 \%$ a praça tem um significado de progresso e crescimento, já que foi uma praça muito importante para o crescimento do município de Bauru, sendo seu projeto original aos moldes europeus; um grande progresso à época.

- Para 9,09\% a praça não apresenta significado algum, sendo um local que representa corrupção (várias transformações e projetos implantados, sem prezar pelo uso que, de fato, agrada a população).

\section{CONCLUSÃO}

Com a caracterização da Praça Rui Barbosa no cronotopo atual, é possível perceber que há vezes em que a gestão pública impõe projetos, ou melhor, espaços públicos urbanos à uma dada sociedade, sem ao menos realizar uma pesquisa sobre os reais interesses ou expectativas dos usuários e muito menos preservar a gênese da praça. O que, a curto prazo, vai levar ao abandono e degradação dessa área, o que leva ao problema citado pela população bauruense: insegurança.

Ainda em relação ao questionário aplicado, foi perguntado à população quais mudanças gostariam que ocorressem na praça. Foram várias as observações apresentadas, sendo as mais pedidas: segurança, melhor paisagismo, existência de atividades culturais e até mesmo a retomada do projeto original. Além dessas pontuações, algumas outras foram mencionadas, como: melhor iluminação, retomada dos lagos e animais, limpeza e manutenção da praça, retirada das drogas, mais lazer, humanização e mais vida.

É importante mencionar, que o projeto que levou à descaracterização total da Praça Rui Barbosa foi implementado em 1990, o projeto instaurado em 2015 se deu como uma revitalização (manutenção) do projeto anterior.

Finaliza-se esta discussão diante da clareza com que o atual projeto da praça não condiz com os ideais de um espaço público para os usuários, ou seja, não atende aos desejos e anseios da população, nem a preservação da gênese da praça. Como a própria população diz, falta vida, falta um local mais humano, que prioriza o uso social e não as vontades de uma gestão que pretende superar a anterior.

\section{AGRADECIMENTO}

Agradecimento especial à todos aqueles bauruenses que dispenderam parte de seu tempo para responder ao questionário aplicado, e que puderam assim contribuir com informações de grande importância para o caminhar desta pesquisa. 
Agradecimento à SEPLAN por tão prontamente disponibilizar o projeto implementado em 2015.

\section{REFERÊNCIAS BIBLIOGRÁFICAS}

ACERVO SECRETARIA MUNICIPAL DE PLANEJAMENTO DE BAURU - SEPLAN.

ALEX, Sun. Projeto da Praça: convívio e exclusão no espaço público. São Paulo: Editora Senac São Paulo, 2008.

BAKHTIN, Mikhail. Estética da Criação Verbal. Tradução Maria Ermantina Galvão G. Pereira. 2 ed. São Paulo: Martins Fontes, 1997.

CARVALHO, Pompeu Figueiredo de; FRANCISCO, José; BRAGA, Roberto. Revitalização de Praças e Jardins nas Áreas Centrais de Cidades Médias Paulistas. In: II ENCONTRO ASSOCIOAÇÃO NACIONAL DE PÓS GRADUAÇÃO E PESQUISA EM AMBIENTE E SOCIEDADE, 2004, Indaiatuba-SP. Anais eletrônicos. Disponível em: <http://www.anppas.org.br/encontro_anual/encontro2/GT/GT14/carvalho_et_alii.pdf>. Acesso em: 19 jun. 2017.

LAMAS, José M. Ressano Garcia. A morfologia urbana. In: Morfologia urbana e desenho da cidade. 7. ed. Lisboa: Fundação Calouste Gulbenkian, 2014. p. 35-129.

MARX, Murilo. As Praças. In: Cidade Brasileira. São Paulo: Melhoramentos, editora da Universidade de São Paulo, 1980. p. 49-57.

MUNTAÑOLA, Josep. Hacia uma aproximación dialógica a la arquitectura contemporânea. In: Revista Arquitectonics. Mind, Land \& Society. Arquitectura y dialogia. Barcelona: UPC, no 13, 2006. p. 63-76.

. El diálogo entre proyecto y lugar: un reto para la arquitectura del siglo XXI. CPA_02 El lugar, p. 33-38, 2011.

ROBBA, Fabio; MACEDO, Silvio Soares. Praças Brasileiras. 2 ed. São Paulo: Editora da Universidade de São Paulo, 2003.

ZÁRATE, Marcelo. ARQUITECTONIS Urbanismo Ambiental Hermenéutico. 1 ed. Barcelona: Edicions UPC, 2014. 2015.

Urbanismo Ambiental Hermeneutico. ARQUITECTONICS Arquitectura y Dialogia. Barcelona: UPC, no 28, 